\title{
The Creation of Beautiful Countryside in the Internet Age: Semantics, Theory and Path-Taking Yuan Ye as an Example
}

\author{
Dong Yue ${ }^{1, \text { a† }}, \mathrm{Li} \mathrm{Gang}^{2, \mathrm{~b} \dagger}$, Wu Zhenzhi ${ }^{3, \mathrm{c} \dagger}$ \\ ${ }^{1}$ Shanghai Art \& Design Academy, Shanghai, China \\ ${ }^{2}$ Shanghai Art \& Design Academy, Shanghai, China \\ ${ }^{3}$ Shanghai Art \& Design Academy, Shanghai, China
}

\begin{abstract}
With the advent of the Internet Age, the rapid development of modern rural construction and urban-rural integration, the revival of traditional culture and environmental improvement and many other factors, the multi-semantic social relationship of the beautiful countryside has been formed gradually based on the space, culture and locality. The reconstruction and reshaping of beautiful countryside in the Mobile Internet Age takes Yuan Ye as a theory and path to improve the quality of Internet rural culture, and combines the current technological innovation to expound such design ideas as poetic charm, adaptation to local conditions and so on in garden culture, injecting new design vitality to the inheritance of cultural resources and construction of modern rural society.
\end{abstract}

\section{CONCEPT}

With the frequent flow of rural population, the rapid development of market economy and the advent of the Mobile Internet Age, multi-support network has become an increasingly common social fact, and play an increasingly important role in rural agricultural industry integration, urban-rural integration, cultural revitalization, intangible heritage inheritance and other processes in the context of rural revitalization. ${ }^{[1]}$ Academician Yang Enhui put forward the idea of "promoting urban construction with culture as the soul". In the process of China's urbanization, "beautiful countryside" has injected new vitality into China's urban and rural planning. However, few people pay attention to the relationship between beautiful rural culture and traditional garden design. Huang Wenhua once proposed: "In most studies, the cultural protection only stays in the material aspect, did not go deep into the design thought connotation". In this context, the garden design which represents the traditional culture can be paid attention to, especially in the process of the urban-rural integration construction, Ji Cheng's Yuan $\mathrm{Ye}^{[2]}$ in the Ming Dynasty can provide certain examples for the space design, as well as guidance for the thoughts of layout, the ecology, humanities, aesthetics, harmony, protection and sustainability of spatial design.

\section{Cultural Connotation of Design in Yuan Ye}

Yuan Ye recorded the design ideas of landscape architecture, constructed the material and spatial relationship between human and environment, and talked about humanistic feelings in several parts, expounding the cultural mapping of the artistic themes such as poetry and painting, historical allusions in the garden design, and instructing the cognitive pursuit of the designers at that time to present a kind of "virtual" form. "Garden Culture" reflects the social ideology and spiritual aesthetic style of garden owners and designers through material entities. From the design perspective, garden languages such as space, form, collocation, proportion, texture, vegetation and layout, convey the social state and the spirit of the times, and form a comprehensive cultural space combined with other cultural categories. At the same time, the idea and content of traditional gardening have important origin with the design of landscape, plants, buildings, roads and other space things in the construction of "beautiful countryside", as well as the creation of regional characteristics and humanistic artistic conception.

In modern urban-rural integration construction and garden design, we should learn and apply the classical artistic ideas and forms of traditional gardening, such as space architecture, road, landscape, vegetation, in order to carry forward the traditional culture, that is, according to the standard of traditional garden design, the beautiful rural environment can also be constructed. Re-reading Yuan Ye in the light of the development of the past and the present provides an innovative basis and a source of 
development for the reconstruction of the beautiful countryside and urban and rural culture in the process of the integration of urban and rural areas. Internet technology has constructed a new form of our society. The diffusion of the network logic has substantially changed the operation and result in the process of production, experience, power and culture. We should face up to the fundamental changes brought by the Internet and big data technology to the rural social formation, because modern information technology can bring the in-depth synergy of rural society. ${ }^{[3]}$ For example, designers (architects, landscape planners, artists) and other groups not only pay attention to physical space (layout, shape, material, structure, etc.), but also social behavior, cultural consciousness, etc. in the process of urban renewal or redesign, that is, in designers' thinking, the urban and rural development innovation is combined with the actual traditional culture, plus Internet thinking and innovative design applications, and the implementation with adaption to local conditions, and further changes and enriches the rural design space of urban-rural integration.

\section{Cultural Shaping Strategy of "Beautiful Countryside" Urban-rural Integration}

\subsection{Inheritance and Utilization: the "Poetic and Picturesque" Design Culture Resources in Yuan Ye}

"Poetry" and "painting" have always been an important carrier of landscape painting in ancient China, and there is a close relationship between poetry and painting in landscape design. The relevant poems quoted in Yuan Ye as the creative text of garden making, site investigation, foundation establishing and view borrowing, that recorded the Ming people's pursuit of landscape design, artistic conception transmission and humanistic spirit, which can provide reference for the "poetic and picturesque" urban-rural construction in modern times.

Site Investigation · Village Land recorded: “A winding path was opened around the fence, and the servant cleaned the fallen leaves and broke the moss", which echoed the rural ecological landscape of "The moss creeping onto the doorsteps turns them green" described by Liu Yuxi in the Tang Dynasty. In Foundation Establishing, "the sentiment of 'river flows beyond heaven and earth' is combined with the sentence of "misty mountain scenery",, which skillfully quoted the poem "The river seemed to run beyond the heaven and earth, and the mountains were always looming in the mist" by Wang Wei in the Tang Dynasty. Although the design volume of architectural form in garden is small, in the spatial position layout, it is necessary to select the high terrain, the surrounding landscape design should highlight the natural state, creating a sense of taking a far-sighted view. In Pavilion Foundation, "ascending a higher level, a broader perspective could be achieved" corresponds to Wang Zhihuan' description of an overlooking scene in the Tang Dynasty, that is, "Ascend another storey to have a further sight". The poems quoted shows that the optimal landscape design and planning should have both closerange green plants to please the eyes and the magnificent prospect of distant landscape. The scene of "a row of white egrets" in View Borrowing quoted Du Fu's Quatrains in the Tang Dynasty: "A row of white egrets ascends the blue sky", which has a poetic and pictorial association from the dynamic creation of objects to the design of spatial scale and ecology, reflecting the ancient people's wishes and feelings in the landscape design through the scenes, colors, light and shadow, situation and so on.

At the same time, officials, poets and painters of all dynasties have created and painted all kinds of paintings and poems for gardens, and garden design also drew on the scenes in the paintings. (Figure 1) In the author's preface of Ji Cheng's Yuan Ye, it pointed out: "I like Guan Tong and Jing Hao's brushwork the most, and often imitated them". It showed that his idea of painting creation was influenced by the ancients, even in the garden design, there are also learning and imitation. Ji Cheng strived to create landscapes by drawing on paintings. For example, in Making Rockery: "creating landscape paintings with profound meaning", and in Making Rockery · Cliff Stone: "to use pollen wall as paper, and to paint with stones; the texture were the wrinkles of the stones, so as to imitate ancient brushwork", all embodied the design of taking gullies to create landscape paintings and creating hills to seek ancient conception in gardens. View Borrowing described: "However, the objects to please the eyes should reflect the deeper yearning; it seems the conception should be established earlier before painting, which would make the portraying more easily". It put forward the method and process of garden design, just as the current design process, to first draw a sketch, make everything clear in mind, then carry out expression. From a certain point of view, the paintings of the ancients can be used as the blueprint of garden design, but the garden space is more complicated than the paintings. It requires designers to learn the paintings and to make natural observation, refining and generalization, and understand the creation of landscape realm, after which, they should have a comprehensive consideration from whole to part and then to whole before construction, so as to present a concrete practical and aesthetic material form at completion, and reach the space standard of "visitable and livable".

From the point of view of ancient gardening, if the gardeners did not have the basis of poetry and prose, they had no source of inspiration. The problem cannot be mixed, poetry derived from different feelings, therefore, suburban garden, urban garden, flat garden, and little court have their own styles, where the layout of pavilions should be appropriate, just like writing articles. ${ }^{[4]}$ Yuan Ye included poetry and painting, in the hope that the living space and natural environment could meet the author's ideal standards.

Then, in view of the destruction of urban and rural space, cultural shrinkage, lack of innovation and homogeneity problems, the "beautiful countryside" construction in urban-rural integration takes Yuan Ye's poetic design as a mirror, which is also a possible way to 
create a beautiful urban and rural picture that is "livable and visitable".

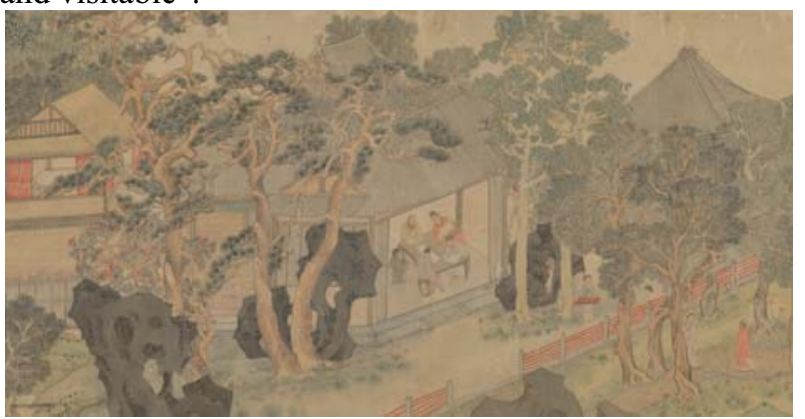

Figure 1: Part of Dongyuan Drawing

\subsection{Appropriateness for All: "Making the Past Serve the Present": Drawing on the Design Ideas of Yuan Ye}

In Yuan Ye, Ji Cheng paid his tribute to the thoughts of his predecessors by referring to their allusions, which presented the ideal state and thinking of gardening in the aspects of scenery selecting and object creation, space allocation and feelings expression, so as to conform to the thoughts of his predecessors.

In the process of promoting the integration of urban and rural areas, the development of rural public space and cultural activities needs to trace back and pay attention to the historical stories, folk traditions, industrial heritage and so on, in addition to the idea of landscape design. Only when the city and countryside are presented with vivid scenery can the identity and cohesion of the common people be strengthened in various forms.

The allusions used in Yuan Ye generally conveyed $\mathrm{Ji}$ Cheng's ideas on three aspects of landscape design: first, the ecological view of valuing nature and leisure; second, the value view of rendering relaxation and transmitting feelings through scenery; third, the Literati view of following the heart and having elegant charm and interest.

First, the ecological view of valuing nature and leisure. According to Pavage: "Lotus blooms under socks, step on it; greenness penetrates the deep forest, where does spring come from." Jicheng designed the garden paving as a lotus pattern, which also gave life and aesthetic interest to the cold paving. The latter part of the sentence quoted Cao Zhi's Ode to the Goddess of the Luo River, "Either picking pearls or green feathers", also expressed that the ground design had a unique beauty and an ecological view that upholds natural beauty. In Site Investigation - Waterside Sites, "Does it like Houling, where Zijin blew the vertical flute? Or does it resemble the abode of immortals, where Emperor $\mathrm{Mu}$ attended upon a banquet". The two allusions derived from The Book of the Later Han, Biography of Wang Qiao: "Emperor Zijin of Zhou (referring to the immortals) was good at blowing the vertical flute, who later flew away on a white crane from the top of Huoling Mountain", and Biography of Emperor Mu of Zhou: "Emperor Mu of Zhou attended upon a banquet and toasted to Queen Mother of the West (a figure in Chinese ancient legends) at the abode of immortals". The two allusions were quoted to express the ecological leisurely fairyland of "blowing the vertical flute and riding on a crane" and "drinking with the immortals" created for gardens located near rivers or lakes.

At present, Guifeng Village, Yangzhong Town, Youxi County, Sanming City, Fujian Province, is located in a semi-high valley, where the buildings were constructed according to the terrain, surrounded by mountains and enjoying a picturesque scenery. In the construction and protection of Guifeng Village, we should respect nature and not destroy the ecology. According to the original natural landscape and architectural form of Guifeng Village, we should repair the damaged local pattern and spatial structure of the early buildings and preserve the characteristics of the ancient buildings built on the mountain, properly improve the rural environment, and always maintain the unique ecological nature, in order to achieve harmony between man and nature. The local people in the countryside are carried in the landscape architectures. To protect and pass on the local folk customs, the traditional folk houses with cultural characteristics should be preserved or repaired or rebuilt, with emphasis on the use of local materials and crafts. In the design of new buildings or structures, it is necessary to extract and analyze their historical evolution and the elements of the existing historic buildings' humanistic characteristics, to merge them into the new buildings, and to add the humanistic sentimental color and artistic conception, fully utilizing and developing local crafts and passing on the traditional technology. ${ }^{[5]}$

Second, the value view of rendering relaxation and transmitting feelings through scenery. For example, in Setting Foundation, "Tao Yuanming wove fences to plant chrysanthemum, the Revered Yu hoed the ridges to plant prune trees". Tao Yuanming, a litterateur of the Eastern Jin Dynasty, once served as magistrate of Pengze for over 80 days, and composed the verses of "While picking chrysanthemum 'neath the Eastern fence, my gaze upon the Southern mountain rests"; in the Song Dynasty, Zhou Dunyi's Ode to the Lotus Flower stated: "Tao Yuanming of the Jin Dynasty only loves lotus"; therefore, the allusion uses "Chrysanthemum" and "Lotus" to highlight the hermit's noble integrity and vegetation design. In View Borrowing: "'Hermits are honored as sages, as well as prime ministers in mountains.' According to Living Idly, 'green grass' is lovable". Li Shizhi in the Tang Dynasty wrote in Dismissed Prime Minister: "Resign from the priesthood to the talents of the wise men; I love my wine so much that I can drink it freely"; Du Fu's Ode to the Eight Sages of Drinking: "Drink wine happily and freely after resignation" was a praise to Li Shizhi. Living Idly refers to Ode to a Leisure Life; "green grass" derived from the "whenever I see green grass, a sense of familiarity would well up in my heart" in Sheng Cha $\mathrm{Zi}$. The Smoke on Spring Mountain is Beginning to Subside (Niu Xiji in the Five Dynasties), which implied the bitterness of love. However, Ji Cheng combined the ideas of gardening in the Ode with the small landscapes of grass in the garden, rendering the feelings with the landscapes, so as to convey a free and easy realm of expectation. Both of the two allusions showed the value of the owner living in seclusion in the mountains and woods, who expressed their feelings with the landscapes. 
Third, the Literati view of following the heart and having elegant charm and interest. For example, in Site Investigation - Outskirt Wild Land: "Enter the garden at will, no matter who its owner is; and there is no need to mention my name", it cited the allusion of Wang Xianzhi's travel to a famous garden in Wuzhong. After entering the garden, though he did not know the owner was, he went into the garden and traveled as if there was no one there; the latter part of the sentence referred to Wang Ziqiu who passes by Wuzhong and was informed that the garden owner loved bamboo; he immediately entered the garden and the owner also received him cordially. These allusions implied the author's unflappable pursuit of the spatial intention of enjoying the scenery and getting along with people. In Site Investigation, spatial design lied in the adaption to the local conditions, as well as allowing people to have fun and communicate harmoniously.

In View Borrowing: "The pleasure of traveling on a boat was unparalleled, and the boiling tea was better than Dang Ji's". "Traveling on a boat" derived from $A$ New Account of the Tales of the World · Willfulness, referring to Wang Huizhi's remark: "why would I insist on meeting Dai when I came at a whim and go with pleasure", the latter part of the sentence mentioned the allusion of "Dangji's Boiling Snow". "Dangji" was a female worshiped by artists in the Ming Dynasty. It not only reflects the pursuit of the ancient Wei and Jin people's free, bold and uninhibited style of living, but also shows the garden owner's leisurely and carefree literati feelings.

The design with allusion to "make the past serve the present" in garden space is the construction and transmission of elegant culture, on the other hand, it makes the objects and scenes in the space reasonable. From the point of view of using allusions, on the basis of displaying Ji Cheng's extensive knowledge, the use of allusions to convey his own gardening ideas can better persuade readers and designers, that is, it contains the design ideas and spiritual pursuit of the predecessors when they visit and build the gardens.

\subsection{Harmonious Coexistence: Excavating its Own Characteristic Culture "according to Local Conditions"}

The "adapting to different conditions" in Ji Cheng's Yuan $Y e$ referred to the combination of nature and human habitation. In dealing with the relationship between nature and human beings, various landscape images are designed according to the aesthetic needs of human beings, to create the space that is "refined in size appropriateness".

The livable environment described in Yuan Ye was divided into three levels, the first level was the original environment around the garden, including topography, vegetation and landscape; the second level was the artificial environment created according to the identity or taste of the owner, including houses, doors and windows, decorations, railings, etc., which were of basic practical use; the third level was a distinctive humanity space created through the design of natural and human living space, which was also what Ji Cheng wanted to express, including the imitation of the predecessors, as well as the "creation" of the owner or designer, achieving the garden making concept and humanistic spirit of "made by people but seeming divined". (Figure 2) "The owner's" or "the designer's" garden construction way, creation skills, aesthetic sense and other factors all adapted to the local conditions.

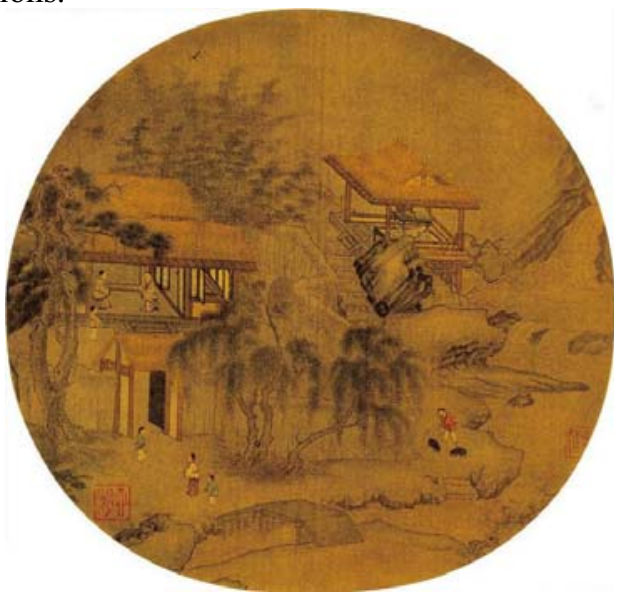

Figure 2: Cottage Dialogue Drawing

According to Yuan Ye $\cdot$ Site Investigation: "The charm of old gardens lied in renovation, natural ancient trees and flowers. Gardening should make use of the natural terrain, whether it is square or round, remote or curved. If the terrain is long and curved, it can be made into a round jade shape; if it is a remote terrain, it can be arranged in layers, just like clouds in the sky". It means to adapt to local conditions, renovate or investigate sites to build new gardens, by using different environmental conditions and studying the geomorphological forms to reasonably make gardens skillfully. In chapters on buildings, decorations, railings, doors and windows, walls and so on, the design was to meet the requirements of the garden making and strive to make the building better coordinated with garden environment. To build gardens at places where the landscape is excellent, it needs as little effort as possible; to make rockery and select stones according to the laws of the composition of the landscape, it should take into account the cost of mining and transportation. In the construction, the plane form, the beam frame structure and the method of construction layout are considered. The original site vegetation should be preserved as much as possible in the design and configuration of matted vegetation and piling up mountains and waters, and the design and life concept of "less is more" should be emphasized in landscape design. Qing Qianyong expressed in Fu Yuan Cong Hua: "The construction of gardens, like writing poetry, should make twists and turns in the structure and leave traces to be found, avoid explicitness, and pay attention to the echoing in the beginning and the end, which is the so-called Leopard Head and Phoenix Tail".[6] In Yuan Ye, it had comprehensive consideration and subtle changes in aspects like site investigation, building walls, rockery setting, railings and floor coverings. From the design point of view, on the basis of satisfying people's residential need, the design of garden space is carried out according to the functions, categories and forms of 
different objects and various construction rules and techniques. There are not only foundations, buildings, decoration manufacturing, but also overall or partial decoration of the space in floor coverings, doors and windows, mountain, stone selection, etc., to present the aesthetic needs of ornamental gardens in different design forms. Some of the design ideas and construction methods can also be used as reference methods for urban and rural architectural spaces and public landscapes. And up to now, the urban and rural design in regions south of the Yangtze River, south Anhui, south of the Five Ridges still follows the ideas methods.

Through the combination of artificial objects and natural objects, the relationship among human, objects and scenery is constructed to achieve the design effect of "refined in size appropriateness" in the limited space. The aesthetic value of gardens also lies in "satisfying the vast ocean of thousands of hectares and collecting the flourishes of the four seasons", to see an infinite space from the limited space. Ji Cheng said "windows are adjacent to emptiness", where the "emptiness" refers to the vast space outside. ${ }^{[7]}$

In a word, the design ideas in Yuan Ye can be applied in the "beautiful countryside" culture shaping in urbanrural integration, and further transform the natural landscape, regional characteristics, urban and rural culture into a unique modern urban-rural space through design. The unique idea and train of thought have certain frontier sense, guidance and culture, which makes the development of rural areas inherently open and inclusive, and provides reference for the construction of local culture.

\section{Conclusion}

In the culture shaping of "beautiful countryside" construction, design power plays a more critical role, and the urban-rural integration construction is imperative. No matter how urbanization develops, it is impossible to "dispel" rural settlements. For human beings, countryside is an indispensable living environment and a civilization of comfortable and beautiful homes. ${ }^{[8]}$ Culture takes urban space as the carrier, and garden design culture as the connotation, and uses the design ideas in Yuan Ye, combined with Internet technology, to promote the display, dissemination and experience of urban and rural space culture, which is also a feature of "beautiful countryside" construction in urban-rural integration.

\section{Acknowledgement}

Project Fund: A Study on the Promotion Effect of the Design Ideas in Yuan Ye on the Development of Urban Culture (Project No.: 2020-A-3-4-28)); Study on the Design of Cultural Symbols of Traditional Residential Buildings in Shanghai in 2019 (Project No. YB2019F03); Multi-dimensional Support of Public Art for the Reconstruction of Old Areas and Social Ecosystem in Shanghai (Project No.: 2020BWY028).

\section{Author}

†Dong Yue (1990.12 - ), male, born in Zibo, Shandong, Lecturer at Shanghai Art \& Design Academy, Master of Arts in Design, Research direction: art design and theoretical research.

†Li Gang (1976.09 - ), male, born in Changtu, Liaoning, Professor at Shanghai Art \& Design Academy, Research direction: art design

†Wu Zhenzhi (1982.10 - ), male, born in Linyi, Shandong, Lecturer at Shanghai Art \& Design Academy, Master of Landscape Architecture, Research direction: Landscape design.

\section{REFERENCES}

1. Guoqiang Hao, Priority Seeking: Reconstruction of Rural Mutual-aid Relationship in the Internet Age [J], The Ideological Front, 2020.02.

2. Zhi Chen, 1988, The quotations in this article derived from the original work of Ji Cheng (Ming Dynasty). Notes to Yuan Ye [M], Beijing: China Construction Industry Press.

3. Chuanzhen Lv, Rural Cooperative Governance Model, Evolution Logic and Path Choice in the Internet Age [J], Journal of Hunan Agricultural University, 2019.12.

4. Congzhou Chen, 2016, Ping Yuan, Nanjing: Jiangsu Phoenix Literature and Art Publishing Co., Ltd, 2016.

5. Yiyang Lu, Manhong Xiao, etc. Discussion on Construction of Ecological Cultural Rural Landscape Based on Chinese Classical Garden Theory [J], Southern Horticulture, 2019.

6. Ji Cheng (Ming Dynasty), Translated by Ni Tai, 2017, Yuan Ye [M], Chongqing: Chongqing Publishing House.

7. Lang Ye, Outline of the History of Chinese Aesthetics [M], 1985, Shanghai: Shanghai People's Publishing House. 1985.11. 445.

8. Wei Zhang, The Universal Value of the Theories in Yuan Ye and Its Guiding Role in Building a Beautiful China [J], Chinese Landscape Architecture, 2012.12. 